\title{
The Relationship between Red Cell Distribution Width, Mean Platelet Volume, Neutrophil to Lymphocyte Ratio and Benign Thyroid Nodules
}

\author{
Kadir Kayataş, (i) Elif Şenocak Taşçı, (1) Muharrem Yıldırım
}

Department of Internal Medicine, University of Health Sciences, Hamidiye Faculty of Medicine, Haydarpasa Numune Health Application and Research Center, Istanbul, Turkey

\begin{abstract}
Introduction: Thyroid diseases are highly associated with the inflammatory process. Red cell distribution width (RDW), mean platelet volume (MPV) and neutrophil to lymphocyte ratio (NLR) are recently used inflammatory markers. In this study, our aim is to investigate the relationship between RDW, MPV and NLR levels and benign thyroid nodules.

Methods: Patients who referred to Haydarpaşa Numune Training and Research Hospital internal medicine clinic between January 2011 and May 2017 were retrospectively analyzed. One hundred-sixty patients with benign thyroid nodules and 30 patients without thyroid nodules fulfilling the inclusion criteria were included in this study. Patients' routine hemogram tests were recorded and RDW, MPV and NLR values were compared between two groups.

Results: The RDW, MPV and NLR values were compared between the group with nodules and the group without nodules. No difference was observed between the groups'MPV or NLR values. RDW values were significantly higher in the group with nodules than the group without nodules ( $p=0.036)$.

Discussion and Conclusion: Our study supports the relationship between thyroid nodules and the underlying inflammatory process. However, unlike some studies suggesting an association between inflammatory biomarkers and malignancy, we do not recommend the use of such markers since they may increase in benign conditions, in distinguishing malignant from benign nodules.

Keywords: Benign; thyroid; inflammation.
\end{abstract}

$\mathrm{T}$ hyroid nodules are encountered very common in clinical practice. According to the data of the American Association of Thyroid, $50 \%$ of the population will develop clinically significant thyroid nodules by the age of $60^{[1]}$. Since the use of imaging techniques becomes widespread, the frequency of thyroid nodules rises. High-resolution ultrasound can reveal thyroid nodules in $19-68 \%$ of the unselected subjects ${ }^{[2]}$. Although most of these nodules are benign, they require long-term monitoring.
Inflammation seems to play a crucial role in thyroid nodule formation. Most of the studies associate inflammation with malignant transformation ${ }^{[3]}$. Novel inflammatory markers, such as red cell distribution width (RDW), mean platelet volume (MPV) and neutrophil to lymphocyte ratio (NLR), are used as inflammatory markers nowadays ${ }^{[3]}$. It has been thought that inflammation and oxidative stress disrupts erythrocyte homeostasis and causes an increase in $\mathrm{RDW}^{[4]}$. On the other hand, MPV is associated with func-

Correspondence (İletişim): Elif Şenocak Taşçı, M.D. Saglik Bilimleri Universitesi Hamidiye Tip Fakultesi, Haydarpasa Numune Saglik Uygulama ve Arastirma Merkezi, Ic Hastaliklari Anabilim Dali, Istanbul, Turkey

Phone (Telefon): +90 5368619817 E-mail (E-posta): esenocak@gmail.com

Submitted Date (Başvuru Tarihi): 12.11.2019 Accepted Date (Kabul Tarihi): 06.12.2019

Copyright 2020 Haydarpaşa Numune Medical Journal

OPEN ACCESS This is an open access article under the CC BY-NC license (http://creativecommons.org/licenses/by-nc/4.0/). 
tional changes in platelets. The increase in MPV is related to the decrease in thrombocyte count and the formation of young and mature thrombocytes that are more active metabolically and enzymatically ${ }^{[5]}$. NLR is frequently used in studies and accepted as an index of the inflammatory response, especially in malignant transformation ${ }^{[6]}$.

Herein, we aimed to investigate the relationship between novel inflammatory markers driven from routine hemogram tests and benign thyroid nodules.

\section{Materials and Methods}

The data of patients who referred to Haydarpaşa Numune Training and Research Hospital internal medicine outpatient clinic between January 2011 and May 2017 were retrospectively analyzed in this study. ICD code recorded in the hospital records was used for scanning. The medical records of the patients diagnosed with benign thyroid nodules after fine-needle aspiration (FNA) biopsy were enrolled and 160 patients fulfilling the inclusion criteria were included in this study. Thirty healthy patients who visited our outpatient clinic for a routine check-up and whose ultrasonographic examinations did not reveal any nodules were included as a control group. The body mass index of patients was between 18.5 and 25; all were accepted as normal weight. The exclusion criteria were as follows: patients diagnosed with acute infection, thalassemia, iron deficiency with or without anemia, infectious diseases, connective tissue diseases, autoimmune diseases, hematological/oncological malignancies, diabetes mellitus, coronary artery disease, subclinical or clinically proven hypo/hyperthyroidism, subacute thyroiditis, renal or hepatic dysfunction, alcohol abuse and pregnancy.

All the laboratory results used were obtained in our hospital's biochemistry laboratory. The blood samples were obtained from the antecubital vein and complete blood count parameters were analyzed using the Mindray BC-6800and ABBOT Architect I200-SR immunoassay analyzer. Hemogram values, white blood cell count (WBC), hemoglobin $(\mathrm{Hgb})$, red cell distribution width (RDW), mean platelet volume (MPV), neutrophil count (neu) and lymphocyte count (lym) were recorded. Neutrophil to lymphocyte ratio (NLR) was obtained by the division of neutrophil to lymphocyte values. Values obtained three months before and after the FNA biopsy or ultrasonographic examinations were used for patient and control groups, respectively. Patients with thyroid nodules with the longest diameter of $\geq 10 \mathrm{~mm}$ ultrasonographically (TOSHIBA APLIO 400) underwent FNA. FNA smears were air-dried with Diff-Quik stain and stained rapidly with ethanol-fixed PAP EA50.
The protocol was approved by the ethical review board of Haydarpaşa Numune Training and Research Hospital. (Number: 6297726-000-12089).

\section{Statistical Analyses}

NCSS (Number Cruncher Statistical System) 2007 (Kaysville, Utah, USA) was used for statistical analysis. While evaluating the data, in addition to descriptive statistical methods (Mean, Standard Deviation, Median, Frequency, Ratio, Minimum, Maximum) distribution of the data were evaluated by the Shapiro-Wilk Test. Pearson correlation was used for the ones with normal distribution and Spearman correlation was used for the ones without normal distribution. Student's t-test was used for comparison of the quantitative data between two groups showing normal distribution, and the Mann-Whitney $\mathrm{U}$ test was used for comparison of two groups, not showing normal distribution. $\mathrm{P}<0.05$ was considered significant.

\section{Results}

We retrospectively reviewed the data of patients referred to Haydarpaşa Numune Training and Research Hospital between 01.01.2011-01.05.2017. A total of 190 patients involved in this study, 160 of whom were diagnosed with benign thyroid nodules after ultrasonographic examination and FNA biopsies, whereas 30 had no thyroid nodules on ultrasonographic examination. The mean age was $49.24 \pm 11.66$ years, and the male to female ratio was 1:4. Table 1 shows demographic characteristics and mean hemogram values of the patients.

The RDW, MPV, NLR and TSH values were compared between the two groups (Table 2). No significant correlation was found between the presence of nodules and MPV or NLR. On the other hand, RDW values were significantly higher in the group with nodules than the group without

Table 1. Demographic characteristics and mean hemogram values of the patients

\begin{tabular}{lc}
\hline Variables & $\mathbf{n}=\mathbf{1 9 0}$ \\
\hline Age (years) & $49.24 \pm 11.66$ \\
Female, $\mathrm{n}(\%)$ & $152(81.7)$ \\
TSH & $1.29 \pm 1.01$ \\
Free T4 & $1.08 \pm 0.16$ \\
RDW & $13.92 \pm 1.14$ \\
MPV & $9.32 \pm 1.39$ \\
NLR & $1.80 \pm 0.56$ \\
\hline
\end{tabular}

TSH: thyroid stimulating hormone; RDW: red cell distribution width; MPV: mean platelet volume; NLR: neutrophil to lymphocyte ratio. 
Table 2. Comparison of RDW, MPV and NLR values between two groups

\begin{tabular}{lccc}
\hline & $\begin{array}{c}\text { With nodules } \\
(\mathbf{n}=\mathbf{1 6 0}) \\
\text { Mean } \pm \text { SD }\end{array}$ & $\begin{array}{c}\text { Without nodules } \\
(\mathbf{n = 3 0 )} \\
\text { Mean } \pm \text { SD }\end{array}$ & p \\
\hline TSH & $1.40 \pm 0.98$ & $2.13 \pm 1.08$ & $0.001^{*}$ \\
RDW & $14.02 \pm 1.19$ & $13.39 \pm 1.09$ & $0.037^{*}$ \\
NLR & $1.84 \pm 0.71$ & $1.64 \pm 0.42$ & 0.434 \\
MPV & $9.30 \pm 1.51$ & $9.48 \pm 1.27$ & 0.536 \\
\hline
\end{tabular}

TSH: thyroid stimulating hormone. RDW: red cell distribution width. NLR: neutrophil to lymphocyte ratio. MPV: mean platelet volume. SD: standard deviation.

nodules ( $p=0.036)$. TSH values were also significantly lower in the group with nodules than the group without nodules $(p=0.001)$. Lower levels of TSH in the nodule group are associated with nodules producing high levels of thyroid hormone. Since the RDW values were found significant, nodules were grouped according to their sizes (Table 3 ). No significant relationship was found between nodule size and RDW values $(p=0.297)$.

\section{Discussion}

Thyroid nodules are frequently seen but mostly asymptomatic. Incidentally found that thyroid nodules are seen $0.08 \%$ in the first years of life while this rate increases in later years, especially in the $80 \mathrm{~s}^{[7]}$. Thyroid nodules have been reported to be more common among women, elderly, people who are exposed to ionized radiation and living in endemic areas concerning iodine deficiency ${ }^{[8]}$. The distinction between benign and malignant thyroid nodules is very important. The malignancy rate of thyroid nodules is $5 \%\left[{ }^{[9]}\right.$. In the present study, we aimed to investigate the association between benign thyroid nodules and easy-accessible inflammatory markers; RDW, MPV and NLR.

RDW, MPV and NLR values obtained during the complete blood count are frequently used as an indicator of inflammation due to their easy accessibility. RDW levels used in the etiology of anemia have been shown to increase in inflammatory bowel disease, Behçet's disease, vasculitis, rheumatoid arthritis and SLE ${ }^{[10]}$. In a study conducted by Aktaş et al. ${ }^{[11]}$ in which RDW levels were compared in benign and malignant thyroid nodules, mean RDW values were found significantly higher in the malignant group than in the benign group. In our study, RDW values were found significantly higher in the group with nodules $(p=0.036)$. Provatopoulou et al. ${ }^{[11]}$ found altered expression levels of interleukins in patients with benign thyroid nodules, sup-
Table 3. Comparison of the RDW values according to nodule sizes

\begin{tabular}{lcc}
\hline & Red Cell Distribution & p \\
\hline $10-20 \mathrm{~mm}$ & $14.03 \pm 1.14$ & \\
$20-30 \mathrm{~mm}$ & $13.97 \pm 1.27$ & 0.297 \\
$30-40 \mathrm{~mm}$ & $14.07 \pm 1.17$ & \\
$>40 \mathrm{~mm}$ & $13.82 \pm 1.26$ & \\
\hline Mann-Whitney U Test. & & \\
\hline
\end{tabular}

porting the association between thyroid diseases and the underlying inflammatory process. Our results are compatible with their study, as RDW values increase in inflammatory processes.

While neutrophil values increase in acute inflammation, low levels of lymphocytes in physiological stress results in high levels of NLO in inflammation ${ }^{[12]}$. In a study conducted by Sit et al., ${ }^{[13]}$ where NLR values of patients with malignant and benign thyroid nodules were compared, NLR values were found higher than the benign and control group. Zeren et al. ${ }^{[14]}$ also found increased values of NLR in malignant thyroid diseases, while Yücel et al. ${ }^{[15]}$ did not find any relationship between NLO values and nodule formation in benign thyroid nodules. In our study, we found NLR values to be similar in benign and control groups. This makes NLR values more significant concerning malignancy. Platelets are known to play a role in the inflammatory process, which is seen as an important marker, especially in cancer pathogenesis, because of its angiogenic, metastatic and proteolytic effects ${ }^{[16]}$. Baldane et al.'s ${ }^{[17]}$ study in which MPV values of the patients with papillary thyroid cancer (PTC), benign thyroid nodules, and control group (without nodules) were compared, MPV value was found to be significantly higher in PTC patients and predicted that it could be used as a marker for PTC risk. Yücel et al. ${ }^{[15]}$ showed that MPV values did not increase in benign thyroid diseases. Our findings were compatible with Yücel et al.'s findings. Similar MPV values were found between the benign and control groups.

Our study has several limitations, including retrospective study design, a relatively low number of control group and exclusion of other inflammatory causes. Since it is not appropriate -not accessible- to perform FNA to nodules with a diameter of $<10 \mathrm{~mm}$, we cannot be sure of the malignancy potential of patients with small-sized nodules. Prospective studies with operated nodules can provide better information about malignancy. Psychiatric disorders are also associated with the inflammatory process. Thus, we might not be able to exclude all the other causes of inflammation, 
especially undiagnosed diseases. A detailed investigation could be carried out on NLR and MPV values and why they increase only in malignant conditions since benign thyroid nodules are also associated with the inflammatory processes.

\section{Conclusion}

This study is valuable since it evaluates several parameters, especially easily accessible ones, in benign thyroid nodules. Given that NLR and MPV values do not differ between the groups with benign thyroid nodules and without thyroid nodules enables them to be used as a guide in malignant conditions. RDW, on the other hand, shows a significant increase in the group with benign thyroid nodules and supports the role of the inflammatory process in the formation of nodules even in the absence of malignancy. However, we need further studies to understand the exact inflammatory mechanism underneath the formation of benign thyroid nodules.

Ethics Committee Approval: The Ethics Committee of Haydarpaşa Numune Training and Research Hospital provided the ethics committee approval for this study (27/02/2019-6297726000-12089).

Peer-review: Externally peer-reviewed.

Authorship Contributions: Concept: K.K.; Design: K.K., M.Y.; Data Collection or Processing: M.Y., E.S.T.; Analysis or Interpretation: K.K., E.S.T., M.Y.; Literature Search: M.Y., E.S.T.; Writing: E.S.T., M.Y.

Conflict of Interest: None declared.

Financial Disclosure: The authors declared that this study received no financial support.

\section{References}

1. American Thyroid Association. Clinical Thyroidology for the Public. Thyroid nodules. 2018. Available at: https://www. thyroid.org/patient-thyroid-information/ct-for-patients/july2018/vol-11-issue-7-p-11-12/.

2. Haugen BR, Alexander EK, Bible KC, Doherty GM, Mandel SJ, Nikiforov YE, et al. 2015 American Thyroid Association Management Guidelines for Adult Patients with Thyroid Nodules and Differentiated Thyroid Cancer: The American Thyroid Association Guidelines Task Force on Thyroid Nodules and Differentiated Thyroid Cancer. Thyroid 2016;26:1-133. [CrossRef]

3. Balkwill F, Mantovani A. Inflammation and cancer: back to Vir- chow? Lancet 2001;357:539-45. [CrossRef]

4. Weiss G, Goodnough LT. Anemia of chronic disease. N Engl J Med 2005;352:1011-23. [CrossRef]

5. Mangalpally KK, Siqueiros-Garcia A, Vaduganathan M, Dong JF, Kleiman NS, Guthikonda S. Platelet activation patterns in platelet size subpopulations: differential responses to aspirin in vitro. J Thromb Thrombolysis 2010;30:251-62. [CrossRef]

6. Gong W, Yang S, Yang X, Guo F. Blood preoperative neutrophil-to-lymphocyte ratio is correlated with TNM stage in patients with papillary thyroid cancer. Clinics (Sao Paulo) 2016;71:311-4. [CrossRef]

7. Tan GH, Gharib H. Thyroid incidentalomas: management approaches to nonpalpable nodules discovered incidentally on thyroid imaging. Ann Intern Med 1997;126:226-31. [CrossRef]

8. Urgancıoğlu i, Hatemi H. Türkiye'de endemik guatr. Cerrahpaşa Tıp Faküktesi 1989;14.

9. Hegedüs L, Bonnema SJ, Bennedbaek FN. Management of simple nodular goiter: current status and future perspectives. Endocr Rev 2003;24:102-32. [CrossRef]

10. Lippi G, Targher G, Montagnana M, Salvagno GL, Zoppini G, Guidi GC. Relation between red blood cell distribution width and inflammatory biomarkers in a large cohort of unselected outpatients. Arch Pathol Lab Med 2009;133:628-32.

11. Aktas G, Sit M, Karagoz I, Erkus E, Ozer B, Kocak MZ, et al. Could Red Cell Distribution Width be a Marker of Thyroid Cancer? J Coll Physicians Surg Pak 2017;27:556-8.

12. Jung J, Park SY, Park SJ, Park J. Prognostic value of the neutrophil-to-lymphocyte ratio for overall and disease-free survival in patients with surgically treated esophageal squamous cell carcinoma. Tumour Biol 2016;37:7149-54. [CrossRef]

13. Sit M, Aktas G, Erkol H, Yaman S, Keyif F, Savli H. Neutrophil to Lymphocyte Ratio is Useful in Differentiation of Malign and Benign Thyroid Nodules. P R Health Sci J 2019;38:60-3.

14. Zeren S, Özbay İ, Bayhan Z, Koçak FE, Ucar BI, Kahraman C, et al. The neutrophil-to-lymphocyte ratio as a diagnostic marker for malignant thyroid diseases. Turkish Journal of Biochemistry 2016;42.

15. Erdogan Yucel E, Demiral Sezer S. Relationship Between the Neutrophil to Lymphocyte Ratio and the Presence and Size of Thyroid Nodules. Cureus 2019;11:e3866. [CrossRef]

16. Kisucka J, Butterfield CE, Duda DG, Eichenberger SC, Saffaripour S, Ware J, et al. Platelets and platelet adhesion support angiogenesis while preventing excessive hemorrhage. Proc Natl Acad Sci U S A 2006;103:855-60. [CrossRef]

17. Baldane S, Ipekci SH, Sozen M, Kebapcilar L. Mean platelet volume could be a possible biomarker for papillary thyroid carcinomas. Asian Pac J Cancer Prev 2015;16:2671-4. [CrossRef] 